\title{
Peran Manajemen Sarana Dan Prasarana Dalam Meningkatkan Mutu Pendidikan Di MI NW 1 Kembang Kerang
}

\author{
Nurul Isnaini ${ }^{1}$, Fizian Yahya ${ }^{2}$, Muahammad Sabri ${ }^{3}$,

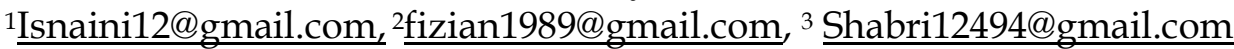 \\ 1,2,3 Manajemen Pendidikan Islam, STAI Darul Kamal, Lombok Timur, Indonesia
}

\begin{abstract}
Abstrak
Penelitian ini bertujuan untuk mengetahui dan mendeskripsikan bagaimana manajemen sarana dan prasarana dalam meningkatkan mutu pendidikan di MI NW 1 Kembang Kerang. Menggunakan metode kualitatif dengan pendekatan deskriptif, data dikumpulkan melalui observasi, wawancara dan dokumentasi. Subjek penelitian adalah kepala sekolah, dewan guru dan waka sarana dan prasarana. Hasil penelitian menunjukan bahwa: (1) Perencanaan pengadaan sarana dan prasarana dengan melihat kebutuhan yang ada, baik kebutuhan kantor maupun kebutuhan belajar mengajar. (2) Pemeliharaan sarana dan prasarana dilakukan oleh semua warga sekolah, baik petugas khusus, kepala sekolah, guru-guru dan murid-murid bertanggung jawab dalam pemeliharaan dan wajib menjaga sarana dan prasarana yang ada di sekolah. (3) Inventaris sarana dan prasarana kegiatan inventaris dilakukan setiap tahun ajaran baru, untuk pencatatan, pembelian sarana dan prasarana selalu melibatkan waka sarana dan prasarana dan kepala sekolah. (4) Penghapusan sarana dan prasarana melalui tahapan dengan memilih barang yang rusak/tidak layak pakai dan sebelum dihapus dilakukan perbaikan kalau masih bisa diperbaiki akan diperbaiki sebaliknya kalau tidak bisa diperbaiki ditaruh di gudang dan di hapus dari daftar inventaris. (5) Pelaksanaan manajemen sarana dan prasarana meliputi: Perencanaan, pengadaan, pemeliharaan, inventaris dan penghapusan.
\end{abstract}

Kata kunci :Manajemen Sarana dan Prasarana, Mutu Pendidikan.

\section{Pendahuluan}

Sekolah sebagai tempat para peserta didik untuk mengembangkan minat dan bakatnya agar tercapai tujuan dari pendidikan sebagai pembentuk karakter seseorang, maka dibutuhkan proses pembelajaran yang sinkron dengan kebutuhan peserta didik dan masyarakat. Untuk mencapai tujuan pendidikan melalui sekolah tentunya harus didukung oleh sarana dan prasarana yang mencukupi sesuai dengan Standar Nasional Pendidikan. Pengelolaan sarana dan prasarana sangat penting karena dengan adanya pengelolaan sarana prasarana yang ada di lembaga pendidikan akan terpelihara dan jelas kegunaannya. Dalam pengelolaan pihak sekolah harus dapat bertanggung jawab 
Jurnal Manajemen dan Budaya STAI Darul Kamal NW Kembang kerang

Volume 1 No 1 Tahun 2021

P-ISSN : 0000-0000

E-ISSN : 2774-6704

https://journal.staidk.ac.id/index.php/mdb

terhadap sarana dan prasarana terutama kepala sekolah yang langsung pun harus dapat menangani tentang pengelolaan sarana dan prasarana tersebut. dan pihak sekolah pun harus dapat memelihara dan memperhatikan sarana dan prasarana pendidikan yang sudah ada. Maka dengan diadakannya sarana dan prasarana siswa pun dapat belajar dengan maksimal.

Proses dalam sistem pendidikan sama pentingnya dengan masukan instrumental dan masukan lingkungan. Semuanya akan menjadi penentu dalam mencapai keluaran (output) dan hasil pembelajaran (outcome). Terkait dengan hal di atas, manajemen sarana dan prasarana mutlak harus diadakan dalam proses pendidikan. Manajemen sarana dan prasarana pendidikan bertugas mengatur dan menjaga sarana dan prasarana pendidikan agar dapat memberikan kontribusi secara optimal dan berarti pada jalannya proses pembelajaran. Agar semua fasilitas dapat digunakan secara optimal dalam proses pembelajaran, maka fasilitas tersebut hendaknya dikelola dengan baik. Pengelolaan sarana dan prasarana yang baik akan terlihat pada mutu suatu lembaga pendidikan.

Hasil observasi awal mutu pendidikan di MI NW 1 Kembang Kerang sudah tergolong sangat baik, dilihat dari proses belajar mengajarnya sudah baik dan guru-guru yang ada disana rata-rata memiliki kualifikasi akademik dan kompetensi sebagai agen pembelajaran yang sehat jasmani dan rohani. Kurangnya fasilitas belajar seperti laboratorium IPA dan media elektronik (audio visual) yang membantu proses belajar mengajar tidak menjadi hambatan untuk bersaing dengan lembaga pendidikan sederajat lainnya. Keadaan sarana dan prasarana yang belum memadai, tetapi mutu yang dimiliki MI NW 1 Kembang Kerang tergolong bagus (akreditasi A+ dengan nilai 95). Ini menajdi indikasi ada manajemen sarana dan prasarana yang baik, mengingat peran manajemen sarana dan prasarana dalam meningkatkan mutu pendidikan cukup besar maka berdasarkan kondisi dan uraian di atas, peneliti tertarik untuk mengetahui lebih jauh tentang pengelolaan sarana dan prasarana di MI NW 1 Kembang Kerang. Sehingga 
Jurnal Manajemen dan Budaya STAI Darul Kamal NW Kembang kerang

Volume 1 No 1 Tahun 2021

P-ISSN : 0000-0000

E-ISSN : 2774-6704

https://journal.staidk.ac.id/index.php/mdb

peneliti melakukan penelitian dengan judul "Manajemen Sarana Dan Prasarana Dalam Meningkatkan Mutu Pendidikan Di MI NW 1 Kembang Kerang"

\section{Kajian pustaka}

Manajemen merupkan suatu kegiatan atau rangkaian kegiatan yang berupa proses pengelolaan usaha kerja sama sekelompok manusia yang tergabung dalam organisasi pendidikan, untuk mencapai tujuan pendidikan yang telah ditetapkan sebelumnya, agar efektif dan efisien ${ }^{1}$. Ada 4 fungsi pokok manajemen yaitu perencanaan (planning), pengorganisasian (organizing), pengarahan (directing/actualing), dan pengawasan (controlling)2 ${ }^{2}$. Dengan begitu, manajemen sarana dan prasarana pendidikan dapat diartikan segenap proses pengadaan dan pedayagunaan komponen-komponen yang secara langsung maupun tidak langsung menunjang proses pendidikan untuk mencapai tujuan pendidikan secara efektif dan efisien. Manajemen Sarana Prasarana Secara umum bertujuan memberikan layanan secara profesional di bidang sarana dan prasarana pendidikan dalam rangka terselenggaranya proses pendidikan secara efektif dan efisien ${ }^{3}$. Di samping itu melalui manajemen sarana dan prasana yang baik diharapkan tersedianya alat-alat atau fasilitas belajar yang memadai secara kuantitatif, kualitatif dan relevan dengan kebutuhan serta dapat dimanfaatkan secara optimal untuk kepentingan proses pendidikan dan pengajaran, baik oleh guru sebagai pengajar maupun murid-murid sebagai pelajar ${ }^{4}$ sehingga dengan sendirinya meningkatkan mutu pendidikan.

Mutu atau kualitas adalah gambaran dan karakteristik menyeluruh dari barang atau jasa yang menunjukkan kemampuannya dalam memuaskan kebutuhan yang

\footnotetext{
${ }^{1}$ Barnawi dan M. Arifin, Manajemen Sarana dan Prasarana Sekolah, (Yogyakarta: Ar-Ruzz Media. 2014), 14

2 Barnawi,Manajemen Sarana Dan Prasrana...21

3 Bafadal, Ibrahim, Manajemen Perlengkapan Sekolah Teori dan Aplikasinya, (Jakarta: Bumi Aksara. 2014), 5 .

${ }^{4}$ Mulyasa, E. Manajemen Berbasis Sekolah, Konsep, Strategi Dan Implementasi. (Bandung: Remaja Rosda Karya, 2003), 50.
} 
Jurnal Manajemen dan Budaya STAI Darul Kamal NW Kembang kerang

Volume 1 No 1 Tahun 2021

P-ISSN : 0000-0000

E-ISSN : 2774-6704

https://journal.staidk.ac.id/index.php/mdb

diharapkan atau yang tersirat ${ }^{5}$. Mutu pendidikan adalah mutu lulusan dan pelayanan yang memuaskan pihak terkait pendidikan. Mutu lulusan berkaitan dengan lulusan dengan nilai yang baik (kognitid, apektif, dan psikomotorik) diterima melanjutkan ke jenjang yang lebih tinggi yang berkualitas dan memiliki kepribadian yang baik. Sedangkan mutu pelayanan berkaitan dengan aktivitas melayani keperluan peserta didik, guru dan pegawai serta masyarakat secara tepat dan tepat sehingga semua merasa puas atas layanan yang diberikan oleh pihak sekolah6. Diantara faktor-faktor yang mempengaruhi pendidikan adalah kurikulum, kebijakan pendidikan, fasilitas pendidikan, aplikasi teknologi informasi dan komunikasi dalam dunia pendidikan, khususnya dalam kegiatan proses belajar mengajar, aplikasi metode, strategi dan pendekatan pendidikan yang mutakhir dan modern, metode evaluasi pendidikan yang tepat, biaya pendidikan yang memadai, manajemen pendidikan yang dilaksanakan secara profesional, sumber daya manusia para pelaku pendidikan yang terlatih, berpengetahuan, berpengalaman dan profesional.

Standar mutu pendidikan terdapat dalam Undang-undang nomor 20 tahun 2003 tentang Sistem Pendidikan Nasional PP No. 19 Tahun 2005 Jo PP No 32 Tahun 2013 dinyatakan bahwa lingkup dari Standar Nasional Pendidikan meliputi 8 standar yaitu standar isi, standar proses, standar kompetensi lulusan, standar pendidik dan tenaga kependidikan, standar sarana dan prasarana, standar pengelolaan, standar pembiyaan, dan standar penilaian. Standar Sarana dan Prasarana adalah standar nasional pendidikan yang berkaitan dengan kriteria minimal tentang ruang belajar, tempat berolahraga, tempat beribadah, perpustakaan, laboratorium, bengkel kerja, tempat bermain, tempat berkreasi dan berekreasi, serta sumber belajar lain, yang diperlukan untuk menunjang proses pembelajaran, termasuk penggunaan teknologi informasi dan komunikasi 8 .

\footnotetext{
${ }^{5}$ Siswanto, Pengantar Manajemen . (Bandung : PT. Bumi Aksara, 2015), 195

${ }^{6}$ Fadhli, M.,"Manajemen Peningkatan Mutu Pendidikan" TADBIR , 1.02 (2017), 218.

${ }^{7}$ Hadis, A.dan Nurhayati, B.Manajemen Mutu Pendidikan.(Bandung: AlfaBeta,2010), 3.

8 Undang-Undang Nomor 20 Tahun 2003 tentang Sistem Pendidikan Nasional. 2003. Jakarta: Depdiknas.
} 
Jurnal Manajemen dan Budaya STAI Darul Kamal NW Kembang kerang

Volume 1 No 1 Tahun 2021

P-ISSN : 0000-0000

E-ISSN : 2774-6704

https://journal.staidk.ac.id/index.php/mdb

\section{Metode penelitian}

Penelitian ini dilaksanakan di MI NW 1 Kembang Kerang terletak di Jl. Segara Anak KM.03 Kec. Aikmel Lombok Timur NTB. Dengan desain kualitatif deskriptif, data dikumpulkan melalui observasi, wawancara dan dokumentasi. Subjek penelitian adalah kepala sekolah, dewan guru dan waka sarana dan prasarana. Pada penelitian ini instrumen penelitiannya adalah peneliti sendiri sebagai instrument utama, kemudian pedoman wawancara dan pedoman observasi. Analisis data pada penelitian ini mengikuti model Milles dan Huberman yang terdiri dari reduksi data, penyajian data dan penarikan kesimpulan. Untuk memperkuat keabsahan data hasil temuan serta mempertahankan validitas data penelitian, peneliti menggunakan empat criteria sebagai acuan standar validitas seperti yang disarankan oleh Licoln dan Guba yang meliputi kredibilitas, keteralihan, katergantungan dan kepastian9.

\section{Pembahasan}

Manajemen sarana dan prasarana yang diterapkan di MI NW 1 Kembang Kerang meliputi beberapa aspek diantaranya perencanaan, pengadaan, pemeliharaan, inventaris dan penghapusan.

1. Perencanaan sarana dan prasarana pendidikan

Perencanaan sarana dan prasarana pendidikan yang ada di MI NW 1 Kembang Kerang selalu diprogramkan, disesuaikan dengan kebutuhan sekolah, dan selalu melibatkan semua pihak dalam merencanakan kebutuhan baik itu kebutuhan kantor maupun kebutuhan pembelajaran. Langkah yang dilakukan di MI NW 1 Kembang Kerang dalam merencanakan sarana dan prasana dirasa sudah tepat karena melibatkan semua pihak untuk mempertimbangkan secara matang kebutuhan sekolah. Karena pada dasarnya perencanaan sarana dan prasarana sekolah dapat didefinisikan sebagai keseluruhan proses perkiraan secara matang rancangan

\footnotetext{
${ }^{9}$ Lexy J. Meleong, Metodologi Penelitian Kualitatif, (Bandung: Remaja Rosdakarya, 2006) , 324.
} 
Jurnal Manajemen dan Budaya STAI Darul Kamal NW Kembang kerang

Volume 1 No 1 Tahun 2021

P-ISSN : 0000-0000

E-ISSN : 2774-6704

https://journal.staidk.ac.id/index.php/mdb

pembelian pengadaan, rehabilitasi, distribusi atau pembuatan peralatan, dan perlengkapan yang sesuai dengan kebutuhan oleh sekolah ${ }^{10}$.

2. Pengadaan sarana dan prasarana pendidikan

Pengadaan merupakan serangkaian kegiatan menyediakan berbagai jenis sarana dan prasarana pendidikan sesuai dengan kebutuhan untuk mencapai tujuan pendidikan.

Pengadaan sarana dan prasarana di MI NW I kembang Kerang dilakukan untuk memenuhi kebutuhan sarana dan prasarana pendidikan agar kegiatan belajar mengajar bisa berjalana dengan lancar. Dalam pengadaan sarana dan prasarana MI NW 1 Kembang Kerang dengan cara memberbaiki dan membeli kalau memang sarana seperti meja, bangku, papan tulis yang dalam keadaan rusak kalau memang masih bisa diperperbaiki akan diperbaiki tetapi apabila tidak dapat diperbaiki maka akan dihapus/dihilangkan dan diganti dengan yang baru. Penagadaan dilakukan sebagai bentuk realisasi atas perencanaan yang telah dilakukan sebelumnya.

3. Pemiliharaan sarana dan prasarana pendidikan

Nurabadi mengemukakan empat macam pekerjaan pemeliharaan, yaitu: (1) perawatan terus menerus, seperti pembersihan saluran drainase dan pembersihan kaca jendela; (2) perawatan berkala, seperti pengecatan tembok dan perbaikan mebel; (3) perawatan darurat, yang dilakukan terhadap kerusakan yang terduga sebelumnya dan jika ditunda akan mengakibatkan hal yang merugikan; dan (4) perawatan prevatif, yakni perawatan yang dilakukan pada selang waktu tertentu dan pelaksanaannya dilakukan secara rutin dengan beberapa criteria yang ditentukan sebelumnya ${ }^{11}$. Pemeliharaan sarana dan prasarana yang diterapkan di MI NW 1 Kembang Kerang berupa pemiliharaan/ perawatan preventif dimana peserta didik setiap masuknya diatur sarana dengan baik yang ada di kelasnya masing-masing supaya terjaga dengan baik. Pemeliharaan sarana dan prasarana di MI NW 1 Kembang Kerang dilakukan oleh semua warga madrasah. Dalam hal

\footnotetext{
${ }^{10}$ Rusydi Ananda dan Oda Kinata Banurea, Manajemen Sarana dan Prasarana, Medan : CV. Widya Puspita, 2017), 36.

11 Rusydi Ananda,Manajemen sarana dan prasarana...50-51
} 
Jurnal Manajemen dan Budaya STAI Darul Kamal NW Kembang kerang

Volume 1 No 1 Tahun 2021

P-ISSN : 0000-0000

E-ISSN : 2774-6704

https://journal.staidk.ac.id/index.php/mdb

pemeliharaan sarana dan prasarana sekolah masih belum maksimal pengelolaannya, bahkan itu menjadi kekurangan MI NW 1 Kembang Kerang setiap menggunakan sarana dan prasarana untuk proses belajar mengajar guru-guru terkadang lupa atau lalai dalam pemeliharaan dan penyimpanannya. Sesudah selsai mengunakan sarana sekolah seperti pengaris, buku-buku guru-guru tidak menaruh di tempat semulanya sarana itu diambil dan sarana tidak digunakan sesuai dengan kebutuhan proses belajar mengajar

4. Inventaris

Inventarisasi MI NW 1 Kembang Kerang kegiatan inventaris sarana dan prasarana dicatat semua barang inventaris ke dalam buku induk barang inventaris dan buku golongan inventaris. Namun untuk pencatatan dan pembelian sarana dan prasarana di sini melibatkan waka sarana dan prasrana dan kepala sekolah. Inventaris pada MI NW 1 Kembang Kerang dilakukan dengan tujuan:

a. Untuk menjaga dan menciptakan tertib administrasi sarana dan prasarana yang dimiliki oleh suatu sekolah.

b. Untuk menghemat keuangan sekolah, baik dalam pengadaan maupun untuk pemeliharaan dan penghapusan sarana dan prasarana sekolah.

c. Sebagai bahan atau pedoman untuk menhitung kekayaan suatu sekolah dalam bentuk materi yang dapat dinilai dengan uang.

d. Untuk memudahkan pengawasan dan pengendalian sarana dan prasarana yang dimiliki oleh suatu sekolah² ${ }^{12}$.

5. Penghapusan

Penghapusan sarana dan prasarana pendidikan yang ada di MI NW 1 Kembang Kerang dilakukan sesuai kondisi sarana yang sudah tidak layak pakai. Barangbarang yang akan dihapus harus memenuhi syarat-syarat tertentu. Menurut Suharsimi Arikunto \& Lia Yuliana (2009:,281-282), barang-barang yang dapat dihapuskan dari daftar inventaris harus memenuhi salah satu atau lehih syaratsyarat di bawah ini.

12 Barnawi, Manajemen Sarana dan Prasarana, ...67-68 
a. Dalam keadaan rusak berat yang sudah dipastikan tidak dapat diperbaiki lagi atau dipergunakan lagi.

b. Perbaikan akan menelan biaya yang sangat besar sehingga merupakan pemborosan uang Negara

c. Secara teknis dan ekonomis kegunaan tidak simbang dengan biaya pemeliharaan.

d. Penyusutan di luar kekuasaan pengurus barang (biasanya bahan kimia)

e. Tidak sesuai dengan kebutuhan masa kini, seperti mesin tulis biasanya diganti dengan IBM atau personal computer.

f. Barang-barang yang jika disimpan lama akan rusak dan tidak dapat dipakai lagi.

g. Ada penurunan efektivitas kerja, misyalnya dengan mesin tulis baru sebuah konsep dapat diselsaikan dala 5 hari, tetapi dengan mesin tulis yang hamper rusak bisa diselsaikan 10 hari.

h. Dicuri, dibakar, diselewengkan, musnah akibat bencana alam, dan lain sebagainya.

Proses penghapusan sarana dan prasarana yang ada di MI NW 1 Kembang Kerang dilakukan melalui tahapan yaitu dengan mengecek, memilih barang yang memang sudah rusak atau tidak layak pakai untuk dihapuskan/dihilangkan dari daftar inventaris dan kalau memang ada sarana yang rusak berat langsung dibawa kedalam gudang.

\section{Kesimpulan}

Manajemen sarana dan prasarana yang diterapkan di MI NW 1 Kembang Kerang sudah melaksanakan semua aspek manajemen sarana dan prasarana (perencanaan, pengadaan, pemeliharaan, inventaris dan penghapusan), meskipun dalam beberapa aspek pelaksanaannya belum maksimal, berikut rinciannya:

1. Perencanaan pengadaan sarana dan prasarana yang ada di MI NW 1 Kembang Kerang dilakukan dengan melihat kebutuhan yang ada, baik dalam kebutuhan kantor maupun dalam pelaksanaan pembelajaran. Sebelum perencanaan pengadaan 
dilakukan terlebih dahulu sekolah melakukan pengecekan terhadap barang yang sekiranya rusak atau tidak layak pakai dari fisiknya jika masih bisa diperbaiki akan diperbaiki, dan kalau fisiknya sudah tidak layak untuk dipakai akan dimasukkan ke gudang sekolah.

2. Pemeliharaan sarana dan prasarana di MI NW 1 Kembang Kerang dilakukan oleh semua warga sekolah baik petugas khusus, kepala sekolah, guru, dan murid-murid yang lain bertanggung jawab memelihara dan menjaga sarana dan prasarana yang ada di sekolah. Setiap 1 semester MI NW 1 Kembang kerang melakukan pemeriksaan sarana dan prasarana yang ada di sekolah supaya sekolah mengetahui sarana dan prasarana yang layak pakai ataupun yang tidak layak.

3. Inventarisasi sarana dan prasarana ini dilakukan dalam rangka usaha menyempurnakan pengurusan dan pengawasan yang efektif terhadap sarana dan prasarana yang dimiliki oleh sekolah. Kegiatan Inventarisasi MI NW 1 Kembang Kerang dilakukan disetiap tahun ajaran baru, untuk pencatatan pembelian sarana dan prasarana selalu melibatkan wakasarana prasarana dan kepala sekolah.

4. Penghapusan sarana dan prasarana bertujuan untuk mengeluarkan atau menghilangkan sarana dan prasarana dari daftar inventaris. Penghapusan sarana dan prasarana di MI NW 1 Kembang Kerang melalui tahapan dengan memilih barang yang sudah rusak atau tidak layak pakai untuk dilakukan penghapusan dari daftar inventaris.

\section{Daftar Refrensi}

Ananda, Rusydi dan Banurea, Oda K, Manajemen Sarana dan Prasarana, (Medan : CV. Widya Puspita, 2017)

Bafadal, Ibrahim, Manajemen Perlengkapan Sekolah Teori dan Aplikasinya, (Jakarta: Bumi Aksara. 2014)

Barnawi dan Arifin, Manajemen Sarana dan Prasarana Sekolah, (Yogyakarta: Ar-Ruzz Media. 2014)

Fadhli, M, Manajemen Peningkatan Mutu Pendidikan, TADBIR , 1.02 (2017)

Hadis, A dan Nurhayati, B, Manajemen Mutu Pendidikan, (Bandung: AlfaBeta, 2010) 
Jurnal Manajemen dan Budaya STAI Darul Kamal NW Kembang kerang

Volume 1 No 1 Tahun 2021

P-ISSN : 0000-0000

E-ISSN : 2774-6704

https://journal.staidk.ac.id/index.php/mdb

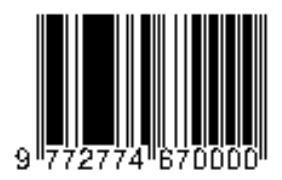

Meleong, Lexy J, Metodologi Penelitian Kualitatif, (Bandung: Remaja Rosdakarya, 2006)

Mulyasa, E. Manajemen Berbasis Sekolah, Konsep, Strategi Dan Implementasi. (Bandung: Remaja Rosda Karya, 2003)

Siswanto, Pengantar Manajemen, (Bandung: PT. Bumi Aksara, 2015)

Undang-Undang Nomor 20 Tahun 2003 tentang Sistem Pendidikan Nasional. 2003. Jakarta: Depdiknas. 